\title{
LEITURA DE/EM FRICÇÃO NA TRAJETÓRIA de Heloísa Buarque de Hollanda
}

\author{
Reading of/in friction in the trajectory of Heloísa Buarque de Hollanda
}

\author{
Cinara Antunes Ferreira ${ }^{1}$ \\ ${ }^{1}$ Universidade Federal do Rio Grande do Sul. Porto Alegre, RS, Brasil. \\ E-mail: cinaraferreira@ufrgs.br
}

\section{RESUMO}

Este ensaio apresenta uma leitura da trajetória da pesquisadora brasileira Heloísa Buarque de Hollanda a partir seus trabalhos, entre os quais 26 poetas hoje (e suas reedições), Explosãofeminista e 29 poetas hoje. Objetiva-se mostrar como a autora realiza deslocamentos epistemológicos a partir de uma contra-narrativa, que se materializa em projetos como a Universidade das Quebradas, as anticonferências, os textos que deixam explícito seu lugar de fala, a antologia de poesia marginal, o livro-ocupação, a antologia de mulheres afinadas com o feminismo, entre outras propostas de intervenção cultural que fazem de Heloísa uma intelectual única no cenário da crítica literária brasileira e latino-americana.

PALAVRAS-CHAVE: Heloísa Buarque de Hollanda; deslocamentos; epistemologia; crítica literária brasileira.

\section{CHEFE:}

Rachel Esteves Lima

EDITOR EXECUTIVO:

Regina Zilberman

SUBMETIDO: 16.10 .2021

ACEITO: 30.10 .2021

\section{COMO CITAR:}

FERREIRA, Cinara Antunes. Leitura de/em fricção na trajetória de Heloísa Buarque de Hollanda. Revista Brasileira de Literatura Comparada, v. 24 , n. 45 , p. $95-101$, jan./ abr., 2022. doi: https:// doi.org/10.1590/2596$304 \times 20222445 \mathrm{caf}$

\section{ABSTRACT}

This essay presents a reading of the trajectory of the Brazilian researcher Heloísa Buarque de Hollanda through her works, among which are 26 poetas hoje (and its reeditions), Explosão feminista e 29 poetas hoje. We aim to show how the author performs epistemological shifts from a counter-narrative, which materializes in projects such as Universidade das Quebradas, the anticonferences, the texts that make her place of speech explicit, the anthology of marginal poetry, occupation-books, the anthology of women in tune with feminism, among other cultural intervention proposals that make Heloísa an unique intelectual in the scenario of Brazilian and Latin American literary criticism.

KEYWORDS: Heloísa Buarque de Hollanda; shifts; epistemology; brazilian literary crticism. 
Aguço o ouvido.

Os aparelhos que só fazem som ocupam o lugar clandestino da felicidade.

Ana C.

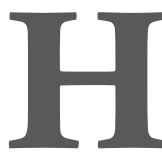
eloísa Buarque de Hollanda é uma intelectual que se destaca no Brasil e no exterior por sua curiosidade e sensibilidade em relação a temas e tendências culturais do seu momento, realizando um trabalho de leitura de/ em fricção, isto é, examinando seus objetos de investigação a partir de perspectivas que relampejam no interior da crítica e da teoria contemporâneas. Com pesquisas voltadas à cultura de resistência, feminismo e periferia, tal posicionamento aparece em suas falas e produção escrita, nas quais busca promover uma ruptura com modelos hegemônicos de produção do conhecimento.

Como deseja Donna Haraway (2019), Heloísa abraça a habilidosa tarefa de reconstruir as fronteiras da vida cotidiana, a partir do seu ponto de vista, negando a noção equivocada de um conhecimento universal, totalizante, que deixa de apreender a maior parte da realidade. Este ensaio pretende mostrar exemplos dessas reconstruções na trajetória da pesquisadora brasileira a partir de alguns de seus trabalhos, entre os quais 26 poetas hoje (e suas reedições), Explosão feminista e 29 poetas hoje.

Em 1976, Heloísa Buarque de Hollanda publica 26 poetas hoje (2021), causando algumas reações negativas por reunir poetas do (seu) tempo presente, entre os quais alguns da chamada poesia marginal, designação controversa naquele momento no meio acadêmico e entre os próprios poetas. Essa antologia é considerada um divisor de águas entre uma poesia canônica e uma poesia contemporânea e performática. A trajetória intelectual de Heloísa é feita de deslocamentos e desarticulações como o dessa antologia. No prefácio da primeira edição de 26 poetas hoje, a autora destaca um modo de olhar para a realidade que pauta sua crítica voltado para o presente:

\begin{abstract}
Curiosamente, hoje, o artigo do dia é poesia. Nos bares da moda, nas portas de teatro, nos lançamentos, livrinhos circulam e se esgotam com rapidez. Alguns são mimeografados. Outros, em offset, mostram um trabalho gráfico sabido e diferenciado do que se vê no design industrializado das editoras comerciais. Mesas-redondas e artigos de imprensa discutem o acontecimento. $\mathrm{O}$ assunto começa- ainda que com alguma resistência - a ser ventilado nas universidades. Trata-se de um movimento literário ou de mais uma moda? E se for moda, foi a poesia que entrou na moda ou foram os poetas? O fato é que a poesia circula, o número de poetas aumenta dia a dia e as segundas edições já não são raras. (2021, p. 26).
\end{abstract}

Heloísa percorre a cidade e observa a circulação da poesia em bares, teatros, lançamentos, artigos e debates. Sem resposta para as questões iniciais que se coloca sobre o evento, segue o seu percurso, desarticulando a crítica ao apresentar jovens poetas que provocavam um deslocamento em relação ao cânone. Em Aula (2007), Barthes nos adverte que as forças de liberdade da literatura não dependem da pessoa civil, do engajamento político do escritor ou do conteúdo doutrinal da obra, mas do trabalho de deslocamento que o escritor exerce sobre a língua. Os poetas em questão fazem esse deslocamento e Heloísa também, ao reuni-los em uma antologia.

Na ocasião do lançamento da obra, a pesquisadora identifica uma poesia que desce da torre do prestígio literário e "aparece com uma atuação que, reestabelecendo o elo entre poesia e vida, 
reestabelece o nexo entre poesia e público. Dentro da precariedade do seu alcance, esta poesia chega na rua, opondo-se à política cultural que sempre dificultou o acesso do público ao livro de literatura e ao sistema editorial que barra a veiculação de manifestações não legitimadas pela crítica oficial." (2021, p. 27) Nessa observação, Heloísa problematiza o papel da crítica oficial na deslegitimação de obras que se afastam do cânone, mostrando-se uma intelectual na contramão da crítica oficial ao olhar para os fenômenos culturais do aqui e agora, percebendo-os antes mesmo que tomem forma e se tornem evidentes para o senso comum.

Nas segunda e terceira edições da obra, a organizadora faz novos prefácios, revendo algumas posições e promovendo novos deslocamentos, resultantes de um olhar distanciado e recontextualizado. Em 1998, ela retoma o contexto histórico em que os poemas foram escritos e a forma como lidou com material tão diverso, buscando um denominador comum que servisse de critério para a sua organização. Ela relata que, na época, identificou que essa poesia apresentava-se como uma alternativa à hegemonia das vanguardas, da tradição cabralina bastante influente naquele momento, e que parecia representar uma retomada do modernismo de 1922: "afirmava isso tomando por base o uso do humor, a invasão dos fatos insólitos e cotidianos no território literário, a presença de uma dicção trabalhadamente informal no olimpo poético, o desejo renitente de aproximar, com um só golpe de linguagem, arte e vida." (2021, p. 22).

Heloísa reconhece, entretanto, que o parentesco com a poesia de 1922 era menos estético do que de intenções: "O que realmente me atraiu nesse material não foi a unidade que eu dizia procurar ao defini-lo para justificar o conjunto dos participantes da antologia, mas, muito pelo contrário, o claro direito ao dissenso que este material começava a reivindicar em nossa produção cultural.” (2021, p. 22-23). Em sua releitura de 1998, a pesquisadora vê com clareza no conjunto uma experiência social da geração AI-5, coibida de narrar sua própria história: "É bem verdade que, na organização deste conjunto, não desgrudei o olho de sua representatividade como registro político naquele momento de extremado rigor da censura." (2021, p. 23).

A partir de uma epistemologia social, a autora fecha o prefácio de 1998, sublinhando que a poesia marginal, mesmo sinalizando mudanças paradigmáticas e declarando-se plural, não anunciou uma inflexão pós-moderna e, tampouco, significou uma reapropriação do modernismo: "prefiro pensar nos 26 poetas como um trabalho irrecusável, visceralmente contextualizado, feito a várias mãos, construindo um cluster político literário que, seguramente, ainda não disse tudo a que veio naqueles idos de 1976." (2021, p. 25).

No prefácio da edição de 2021, Heloisa conta como o livro nasceu, evidenciando seu interesse pela contracultura naquele momento:

Por volta de 1974-5, eu estava particularmente interessada na capacidade de resposta e resistência das expressões contraculturais no contexto de censura e repressão da ditadura pós AI-5. Eram tempos de prisões e exílios - forçados ou voluntários -, que levaram embora os protagonistas das artes, da mídia e da Academia, tempos que o mestre Zuenir Ventura batizou como o 'vazio cultural', expressão que se tornou consenso entre os críticos de cultura. (2021, p. 12).

Observa-se aqui o relato das motivações da pesquisadora com uma assumida vocação para a investigação das microtendências e seu cruzamento com a política no campo da cultura. Nesse 
sentido, a poesia marginal lhe pareceu muito significativa como objeto de análise e como forma de enfrentamento do vazio cultural ditado pela censura. Além de uma confirmação de uma crítica de deslocamento em relação a modelos hegemônicos de crítica, constata-se uma crítica realizada em/de fricções entre a cultura e a política.

Ainda no prefácio de 2021, ao refletir sobre as ferozes críticas que a antologia dos 26 poetas hoje recebeu entre críticos e escritores, Heloísa lembra de sua sensação de surpresa e sua intuição de que tanto incômodo deveria significar alguma coisa. E isso se confirmou pela entrada definitiva da obra para o cânone literário, por sua inclusão nas leituras obrigatórias de concursos de vestibular e por duas reedições.

Em 2021, a teórica lança As 29 poetas hoje (2021) que, ao contrário da primeira antologia, que tinha apenas três nomes femininos entre seus autores, traz só mulheres. Nesse prefácio, escrito em primeira pessoa, chama a atenção a ênfase ao caráter pessoal que Heloísa imprime às suas formulações, já anunciado no título "É importante começar essa história de algum lugar, ainda que arbitrário". Nesse título, que pontua o aspecto arbitrário de qualquer história que se conte, é possível observar uma posição epistemológica de desarticulação da crítica hegemônica, baseada em verdades universais. Isso reflete a trajetória profissional de Heloísa Buarque de Hollanda que, segundo suas palavras, foi "quase que totalmente voltada para pesquisas sistemáticas sobre a injustiça epistêmica e as estruturas institucionais colonizadas e fechadas a qualquer interpelação estética, política ou existencial.” (2021, p. 18).

A autora inicia o prefácio, falando de Ana C., poeta que exerceu e exerce grande atração, sendo apontada por poetas mulheres de forma recorrente como o início de tudo. Heloísa não se concentra nessa questão em especial, mas ressalta a importância da reflexão seminal de Ana C. sobre as relações poesia-feminino-feminismo, para pensar o momento atual da explosão feminista, por defender uma escrita de mulher à deriva e livre de amarras. Para a pesquisadora, a poesia de Ana C. busca dar voz aos temas de mulher, sem cair nas fórmulas poéticas ou políticas:

\begin{abstract}
Numa leitura bastante pessoal, eu diria que Ana C. não chegou a definir o que para ela seria uma poética de mulheres, mas sem dúvida perseguiu, determinada, uma estratégia da poesia de mulheres em busca de uma escrita livre das marcas da delicadeza e da sensibilidade, uma escrita suficientemente porosa que pudesse acolher os tais "temas de mulher". (2021, p. 11).
\end{abstract}

A autora destaca que, ainda que de forma arbitrária, podemos dizer "que Ana foi o solo do que eu chamaria de jovem cânone da poesia de mulheres, a saber: Angélica Freitas, Marília Garcia, Alice Sant’Anna, Ana Martins Marques e Bruna Beber.” (2021, p. 11). Na sequência do texto, numa nova seção intitulada "Inventando um jovem cânone", discorre sobre a poesia de jovens escritoras que, de uma forma ou de outra, influenciam as autoras reunidas em As 29 poetas hoje. Percebe-se, pela linguagem, o propósito de deixar evidente o quanto um cânone é arbitrário, mesmo quando se quer estabelecer um cânone a partir da margem, como é o caso da literatura de autoria de mulheres.

Após mostrar algumas relações entre as poetas do jovem cânone e Ana C., Heloísa aponta Angélica Freitas como o elo entre a geração Ana C. e a nova geração feminista. Para a estudiosa, Angélica Freitas é a grande referência da poesia feita por jovens feministas: "Resumindo: Angélica abriu para as jovens o caminho da desobediência, do corpo, de que escrever é investigar o avesso das regras que regem a 
poesia. Ao mesmo tempo, Angélica é, em sua geração, a que mais abertamente explicitou sua posição feminista." (2021, p. 24).

Como Heloísa está sempre em movimento em seu fazer crítico, não se incomodando em rever e ressignificar suas posições, ela expressa seu desconforto com os rótulos e se faz questões importantes sobre a poesia produzida hoje pelas mulheres:

Diante da onda feminista que nos surpreende hoje, me fiz uma pergunta inevitável: existe uma poesia feminista? Por outro lado, uma segunda pergunta atropela a primeira: seria possível nomear uma poesia como feminista? Não estaríamos promovendo um reducionismo perigoso? Não me sinto confortável chamando essa nova poesia de feminista. Prefiro pensar no impacto do feminismo nessa nova geração de mulheres. (2021, p. 24).

Aqui se percebe a mesma preocupação de Ana C., antes referida, com a possibilidade de uma escrita feminina à deriva e sem amarras. Mais uma vez, Heloísa mostra-se cuidadosa com os reducionismos, a partir dos quais uma análise pode encarcerar uma obra ou um conjunto de obras em classificações estanques, apontando para uma crítica em fricção com o contexto social e político de seu momento presente: "Prefiro pensar numa poética que, agora, passa a ser modulada por uma nova consciência política da condição da mulher e do que essa consciência pode se desdobrar em linguagens, temáticas e dicções poéticas.” (2021, p. 24).

Assim como nos prefácios anteriores, ela conta de sua experiência de pesquisa e seu modo de lidar com o material que encontra, que lembra, de alguma forma, a experiência dos 26 poetas hoje: "De novo me deparo com uma poesia criativa, direta, com estilo próprio, que reinventa o lugar da poesia e enfrenta um momento de alta voltagem conservadora. De novo uma poesia que surge aparentemente sem aviso prévio, como uma surpresa, sem grandes antecedentes, e imprime sua dicção particular na cena literária e política. (2021, p. 25).

Ao final do prefácio, Heloísa destaca a riqueza do corpus que constitui As 29 poetas hoje, evidenciando a diversidade das vozes sociais ali presentes e dos meios através dos quais essas vozes ecoam, o que dialoga muito com o nosso tempo. Existe uma aproximação com a antologia de 1976, principalmente no que diz respeito ao fato das antologias parecerem um só poema, como sugere Cacaso em relação aos poemas marginais. No entanto, a antologia das 29 poetas inclui:

muitas vozes fora do eixo dominante, heteronormativo e branco: são vozes lésbicas, vozes negras, vozes trans, vozes indígenas, interseccionais. Além dessa sintonia fina, em que pese sua heterogeneidade formal, vemos que essa poesia, por sua própria natureza de ter sido historicamente silenciada, desenvolve uma série de estratégias em forma de iniciativas articuladas e coletivas. São blogs, hashtags, sites, coleções, coletivos, editoras independentes, antologias, muitas antologias. (2021, p. 31-32).

Na perspectiva da diversidade, Heloísa publica em 2018 Explosão feminista: arte, cultura, política e universidade, obra que ela chama de livro-ocupação, por acolher os múltiplos feminismos que ocupam diversos lugares na cultura. Dividido em quatro partes, o livro dá espaço para distintas vozes que falam a partir da rua, da rede, da política, das artes, dos grupos sociais marcados pela interseccionalidade (feminismo negro, feminismo indígena, feminismo asiático, transfeminismo, feminismo lésbico, feminismo radical, feminismo protestante), sem deixar de registrar a memória das feministas da terceira onda. 
Comprometida com o lugar de fala, Heloísa abre o livro-ocupação com a introdução intitulada "O grifo é meu", falando do seu próprio lugar: "Sou uma feminista da terceira onda. Minha militância foi feita na academia, a partir de um desejo enorme de mudar a universidade, de descolonizar a universidade, de usar, ainda que de forma marginal, o enorme capital que a universidade tem." (2018, p. 11). Em capítulo que abre a terceira parte do livro, intitulada "Os feminismos da diferença", ela específica ainda mais de que lugar fala: "Nesse quadro, acho importante demarcar de onde parte minha fala: professora, 79 anos, mulher, branca e cisgênero, como adiantei no título. Passei por um longo exercício de escuta, no sentido de reconhecer e acolher as diferenças, reconhecimento que quase nunca vem sem conflito." (2018, 252).

Nesse texto, além de marcar seu lugar de fala privilegiado, a pesquisadora, ao citar Grada Kilomba, nas suas interrogações sobre fala e escuta, pergunta-se se estamos realmente ouvindo e adverte que "a realidade mostra que a escuta é bem mais difícil e perigosa do que parece." (2018, p. 241). Dessa forma, a autora salienta a necessidade de pensarmos de que lugar falamos e como estamos ouvindo as diferentes demandas do(s) feminismo(s). E completa: "Porém, insisto, demoramos muito para escutar as diferenças entre as mulheres e, ainda assim, continuamos escutando pouco." (2018, p. 244).

Além de legitimar o lugar de fala, sua proposta de um livro-ocupação faz ouvir essas vozes que falam/gritam de diferentes lugares. Trata-se de um livro que coloca em diálogo diversos saberes, aproximando-se do que Boaventura de Souza Santos chama de Epistemologias do Sul, proposta epistemológica que tem como ideal a descolonização do saber. Nesse sentido, segundo Santos, a resistência política deve ter como postulado a resistência epistemológica (2009, p. 37). Logo, o que Heloísa Buarque de Hollanda faz em Explosão feminista, assim como nas antologias 26 poetas hoje e As 29 poetas hoje, é promover a resistência política, que passa necessariamente pela resistência epistemológica.

É importante destacar que a leitura de/em fricção realizada por Heloísa está em consonância com o pensamento crítico latino-americano, que se estabelece no continente a partir dos anos 1960, promovendo um deslocamento epistemológico, como aponta Walter Mignolo (2003), que resulta em uma contra-narrativa moderna. Conforme afirma em entrevista de 2019, a pesquisadora não se reconhece como uma acadêmica tradicional, pois tem um projeto político e afetivo de invenção na universidade e se dedica a ele (BOTELHO et al, 2019, p. 26). Portanto, podemos dizer que Heloísa Buarque de Hollanda realiza ao longo de sua trajetória intelectual um deslocamento epistemológico a partir de uma contra-narrativa, que se materializa em projetos como a Universidade das Quebradas, as anticonferências, os textos que deixam explícito seu lugar fala, a antologia de poesia marginal, o livro-ocupação, a antologia de mulheres afinadas com o feminismo, entre outras tantas iniciativas que fazem de Heloísa uma intelectual única no cenário da crítica literária brasileira e latino-americana.

\section{REFERÊNCIAS}

BARTHES, Roland. Aula. São Paulo: Cultrix, 2007.

BOTELHO, José et al. (orgs). Heloísa Buarque de Hollanda. 8.0. Onde é que eu estou? Rio de Janeiro: Bazar do Tempo, 2019. 
HARAWAY, Dona. Manifesto ciborgue: ciência, tecnologia e feminismo-socialista no final do século XX. In: HOLLANDA, Heloísa Buarque (org.). Pensamento feminista: conceitos fundamentais. Rio de Janeiro: Bazar do Tempo, 2019. p. 157-210.

HOLLANDA, Heloísa Buarque (org.). Explosão feminista: arte, cultura, política e universidade. São Paulo: Companhia das Letras, 2018.

HOLLANDA, Heloísa Buarque (org.). 26 poetas hoje. São Paulo: Companhia das Letras, 2021.

HOLLANDA, Heloísa Buarque (org.). As 29 poetas hoje. São Paulo: Companhia das Letras, 2021.

MIGNOLO, Walter. Histórias locais / projetos globais. Tradução de Solange Ribeiro de Oliveira. Belo Horizonte: Ed. UFMG, 2003.

SANTOS, Boaventura de Souza. Para além do Pensamento Abissal: das linhas globais a uma ecologia de saberes. In: SANTOS, Boaventura de Souza; MENESES, Maria Paula (orgs). Epistemologias do Sul. Coimbra: Ed. Almedina, 2009. p. 23-72. 